\title{
Research on Reasonable Width of Coal Pillars of Non-equal Width Isolated Working Face Heading Goaf in Deep Mine
}

weili yang ( $\sim$ yangwl66@163.com )

Zhongyuan University of Technology

Quande wei

University of Science and Technology Beijing

Zhonghui Wang

zhong yuan gong xue yuan: Zhongyuan University of Technology

Zhizeng Zhang

zhong yuan gong xue yuan: Zhongyuan University of Technology

Xiaocheng Qu

University of Science and Technology Beijing

Jinglin Wen

China Academy of Safety Science and Technology

\section{Research Article}

Keywords: deep mine, isolated working face, heading goaf, coal pillars, reasonable width, rock burst

Posted Date: May 28th, 2021

DOI: https://doi.org/10.21203/rs.3.rs-483480/v1

License: () (1) This work is licensed under a Creative Commons Attribution 4.0 International License. Read Full License

Version of Record: A version of this preprint was published at Geotechnical and Geological Engineering on August 14th, 2021. See the published version at https://doi.org/10.1007/s10706-021-01963-0. 


\title{
Research on Reasonable Width of Coal Pillars of Non-equal Width Isolated Working Face Heading Goaf in Deep Mine
}

\author{
Weili $^{1}$ Yang, Wei Quande ${ }^{2}$, Wang Zhonghui ${ }^{1}$, Zhang Zhizeng ${ }^{1}$, Qu Xiaocheng ${ }^{2}$, Wen Jinglin ${ }^{3}$ \\ 1. Architectural engineering department, Zhongyuan University of technology, Zhengzhou, Henan 451191, China; \\ 2. Beijing Anke Xingye Research Institute Company Limited of Mine Safety Technology, Beijing 102299, China; \\ 3. China Academy of Safety Science and Technology, Beijing 100012, China.
}

\begin{abstract}
Setting reasonable coal pillar is a key to ensure safe mining of island coal face heading goaf in deep mine. With determination of reasonable width of coal pillars of non-equal width isolated working face 3201 in worked-out area in one mine in Shandong as the engineering background, a research was conducted on the mechanism of rock burst induced by and the reasonable width of coal pillars of isolated working face in worked-out area and the main conclusions are as follows: (1) the coal pillars of isolated working face 3201 in worked-out area changed from pillars with goaf on two sides $\rightarrow$ pillars with goaf on three sides $\rightarrow$ pillars with goaf on four sides, resulting in evolution of overlying strata from pre-mining static " $\urcorner$-shaped" structure $\rightarrow$ "C-shaped" structure $\rightarrow$ "O-shaped" structure and corresponding spatial stress from "saddle-shaped" profile $\rightarrow$ "platform-shaped" profile $\rightarrow$ "arch-shaped" profile; (2) the rock burst was induced by coal pillars, because the high stress on coal pillars at critical state of a rock burst was greater than their comprehensive strength and induced a rock burst due to sudden instability; (3) by establishing a bearing and load model of coal pillars at critical state of a rock burst and based on the equilibrium relation, an method for estimating reasonable width of coal pillars of isolated working face in worked-out area in deep mine was derived and applied to the isolated working face 3201 in worked-out area, thus comprehensively determining that the width of coal pillars should be $130 \mathrm{~m}$. The field stress monitoring verified the reasonability. The research result is of great significance to prevention of rock burst induced by coal pillars of isolated working face in worked-out area in deep mine.
\end{abstract}

Key words: deep mine; isolated working face; heading goaf; coal pillars; reasonable width; rock burst

With gradual exhaustion of easily available coal resources, the coal resources on corner coal pillars, protection coal pillars and isolated working faces gradually gain popularity. Where, the coal on isolated working faces are the key resources to be recovered. Isolated working faces, which are often of complicated shapes, are formed as a result of non-continuous mining due to geologic structure and mining technologies etc. in previous mining. Furthermore, mining is often advanced toward worked-out area. Generally, rock burst occurs as long as the working face is advanced toward worked-out area. For instance, on March 16, 2012, during excavation of transportation roadway toward worked-out area on working face 2224 at Suncun coal mine, the rock burst caused damage to roadway at about 30m behind; on February 28, 2009, during backward mining on working face 2013 in worked-out area 2105 in one mine, the rock burst caused damage to 260 meters of roadway in the surrounding area ${ }^{[1]}$. Compared with general working faces, the isolated working faces in worked-out area will cause more severe rock burst ${ }^{[2-5]}$. To effectively control the disaster of rock burst caused by isolated working face in worked-out area, coal pillars are often reserved to separate it from the worked-out area. When the width of coal pillars is $3 \sim 10 \mathrm{~m}^{[6-9]}$, the coal pillars are able to timely yield into a plastic state and lose carrying capacity for overlying strata, thus achieving satisfactory prevention and control effect. However, in mining toward the worked-out area, since there is a great distance between the isolated working face and the worked-out area, crossing over "critical width" is required to form small $3 \sim 10 \mathrm{~m}$ coal pillars. Currently, it's not clear what reasonable "critical width" will prevent rock burst without wasting resources. In this article, with the typical deeply buried non-equal width isolated working face in worked-out area as the engineering background, a research on reasonable width of coal pillars was conducted through 
theoretical analysis and field measurement, so as to provide basis for design of width of coal pillars of isolated working faces in worked-out area.

\section{Project overview}

The working face 3201 in one mine in Shandong was a non-equal width isolated working face, as shown in Figure 1. The working face had a burial depth of about $670 \mathrm{~m}$ and a strike length of $1644 \mathrm{~m}$. The width was $140 \mathrm{~m}$ at the narrow section and $246 \mathrm{~m}$ at the wide section. At the narrow section, there was a thorough worked-out area with a total width of $610 \mathrm{~m}$ on the north and a $188 \mathrm{~m}$-width wider part of worked-out area 3203 on the south; at the wide section, there was a $88 \mathrm{~m}$-wide worked-out area on the north and a $88 \mathrm{~m}$-width narrow part of worked-out area 3203 on the south. The coal seam is $3.8 \mathrm{~m}$ thick with an inclination of $1 \sim 13^{\circ}$ and a unidirectional compressive strength of $20 \mathrm{MPa}$, showing a strong tendency of rock burst. The drilling near the working face suggested the distribution of overlying strata, as shown in Table 1. The basic roof was $30.7 \mathrm{~m}$-thick medium sandstone; $12.7 \mathrm{~m}$-thick and $14.8 \mathrm{~m}$-thick medium sandstone was distributed at $135.1 \mathrm{~m}$ and $150.7 \mathrm{~m}$ above the coal seam; the basic bottom stratum was $9.3 \mathrm{~m}$-thick medium sandstone. There were no other thick hard stratum.

Due to non-equal width of isolated working face 3201, mining at wide section of the working face was carried out toward the large worked-out area. With expansion of working face, a coal pillar was formed between the new and previous worked-out areas. In order to prevent rock burst due to instability of coal pillar, a research on reasonable width of coal pillar should be conduced to provide basis for mining design.

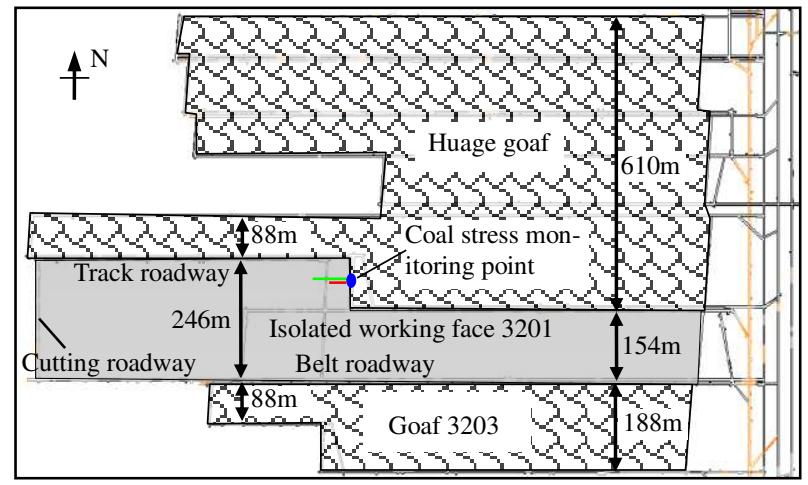

Fig. 1 Plane of non-equal width isolated working face 3201

Table 1 Distribution of overlying strata above coal seam as revealed by drilling nearby

\begin{tabular}{cc||cc}
\hline Rock stratum & Thickness/m & Rock stratum & Thickness/m \\
\hline Top soil & 472.9 & Medium sandstone & 1.5 \\
Fine sandstone & 5.37 & Siltstone & 1.7 \\
Mudstone & 2.97 & Mudstone & 5.94 \\
Fine sandstone & 4.66 & Siltstone & 15.2 \\
Mudstone & 25 & Siltstone & 4.5 \\
Medium sandstone & 14.8 & Medium sandstone & 7.7 \\
Mudstone & 2.9 & Sandy mudstone & 17.7 \\
Medium sandstone & 12.7 & Siltstone & 18.6 \\
Siltstone & 3.2 & Fine sandstone & 3.1 \\
Sandy mudstone & 12 & Medium sandstone & 30.7 \\
Fine sandstone & 1.7 & Siltstone & 1.5 \\
Mudstone & 5.6 & Upper 3 ${ }^{\text {rd }}$ coal & 3.8 \\
Medium sandstone & 3.2 & Siltstone & 6.1 \\
Mudstone & 1.26 & Medium sandstone & 9.3 \\
\hline
\end{tabular}

\section{The mechanism of rock burst induced by coal pillars of the non-equal width isolated working face in worked-out areas in deep mine}

As to the mechanism of rock burst, the common opinion is that it is caused by stress, that is, rock burst will occur as long as the stress of coal mass satisfies the critical stress conditions ${ }^{[10]}$. With regard to in-depth 
mining, the movement of stratum, which cause change of coal mass, is far beyond adjacent strata in height and the boundary of the working face in width, as it is not determined by fracture and movement of one stratum but by structure and movement of overlying strata above the worked-out area. The rock burst caused by coal pillars of the non-equal width isolated working face 3201 in worked-out area was an inevitable result of accumulation of stress of coal mass due to transformation of strata structure.

\section{1 "7-shaped" strata structure of coal pillar before mining}

Before the mining at non-equal width isolated working face 3201, the two sides of coal pillar to be reserved were worked-out areas of coal seam. Due to early formation, the movement of overlying strata had been stabilized. Within the worked-out areas on the two sides, the fractured overlying strata formed a " $\neg$ -shaped" structure when viewed in planar projection, as shown in Figure 2(a). On one side of "-" structure, it could be approximately divided into "caving zone(I)", "fissure zone(II)" and "static load zone" bottom up in vertical direction, as shown in Figure 2(b). Caving zone: the bottom-up fracture and caving of overlying strata. The caved strata immediately filled the worked-out area and was compressed. However, in the area near the coal pillar, caving was inadequate due to support by the "framework" of basic roof, thus forming a strata structure with bearing capacity together with the basic roof. One of this structure was on the substance coal and the other end on the gangue in the worked-out area. Fissure zone: Fissure zone was located above the caving zone and was less influenced by mining. Due to non-development or inadequate development of fissure, the strata would bend and separate from the upper stratum because of its own gravity and kept stable for a long time. In this zone, one end of the strata was located on the coal mass in the area where coal pillar would be reserved and the other end on the other side of the worked-out area. Static load zone: Static load zone was located above the fissure zone and was not influenced by mining. This zone applied static influence on coal mass in the area where coal pillar would be reserved. The stress generated by suspended stratum in caving zone, fissure zone and static load zone was superposed on the coal mass in the area where coal pillar would be reserved to form static bearing pressure 1, as indicated with red curve in Figure 2(b).

On “I” side of “ ᄀ-shaped” overlying strata structure, the east large worked-out area was adequately mined. The caved overlying strata was expanded to the earth's surface and compressed layer by layer bottom-up to the earth's surface. However, due to the support of basic roof, the strata between the gangue line and lock movement line was suspended. The load of suspended strata formed static bearing pressure on the coal mass in the area where coal pillar was reserved, as indicated with red curve in Figure 2(c).

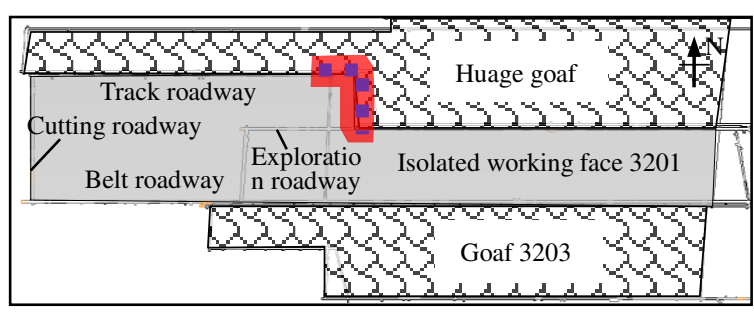

(a) The plan of "ᄀ -shaped" overlying strata structure

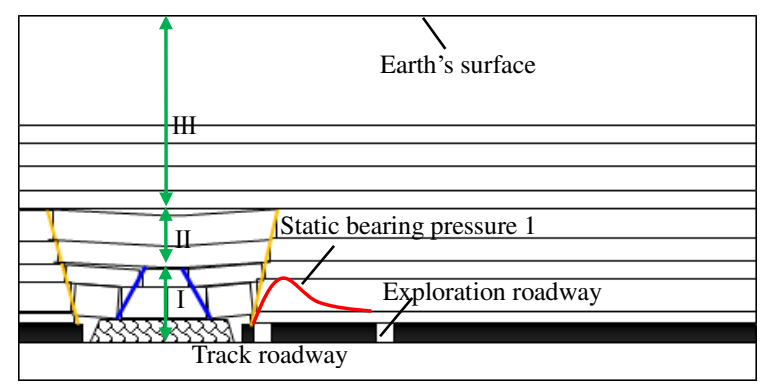

(b) Profile of “-" side of "ᄀ -shaped" overlying strata load structure 


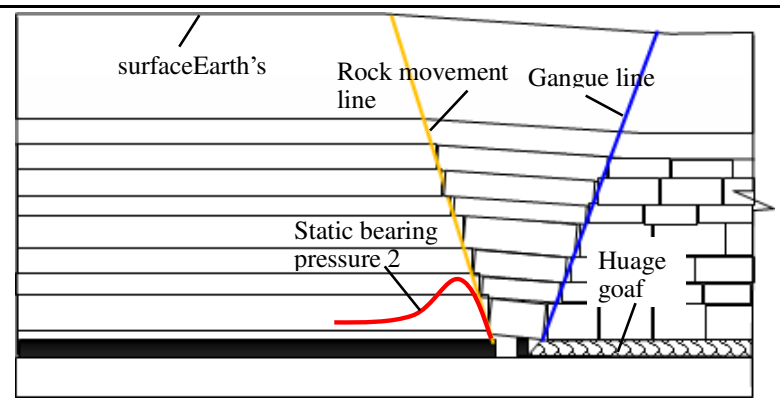

(c) Profile of "l" side of "ᄀ -shaped" overlying strata load structure

Fig. 2 Static "ר -shaped" overlying strata structure of coal pillar before mining

\subsection{Transformation of overlying structure in mining toward worked-out area}

At the non-equal width isolated working face 3201, the mining was advanced from the cutting roadway along the worked-out area which was $80 \mathrm{~m}$ away from north side. With advancing of mining, the immediate roof kept caving and was gradually suspended. When it reached the extreme span, there was initial fracture. The fractured basic roof formed a " $\Gamma^{-}$shaped" structure with the overlying strata in the worked-out area $80 \mathrm{~m}$ away from north side, as shown in Figure 3(a). The lateral bearing pressure (the same as the red curve 1 in

Figure 2(b)) distributed on the "-" side of the structure acted on the foremost coal mass. The "l" side (working face side) of the structure formed foremost bearing pressure, as shown in Figure 3(b). With advancing of mining on the working face, the basic roof was in a process of periodic fracture stage. The " $r$-shaped" overlying strata structure developed continuously. When the single working face became square (246m away from the cutting roadway, 1-1 position as shown in Figure 3(a)), the height, foremost bearing pressure and influence range of overlying strata structure reached the maximum value during mining on the single working face. With continuous mining on the working face, " $\Gamma$-shaped" overlying strata evolved continuously and the peak foremost bearing pressure and influence scope were also increased continuously. When the double working faces became "square" (334m away from the cutting roadway, 2-2 position as shown in Figure 3(a)), the height, foremost bearing pressure and influence range of " $\Gamma$-shaped" overlying strata structure reached the maximum value during mining on the single side along the worked-out area. Then, the working face was further expanded. When it was expanded to 3-3 position (434m away from the cutting line) as shown in Figure $3(\mathrm{a})$, the mining was carried out on both sides. The " $\Gamma$-shaped" overlying strata structure was expanded continuously upward, until the bedrock was totally caved. Then, the topsoil at the depth of 472.9 also caved, accompanied by reduced peak foremost bearing pressure and influence range. The " $\Gamma$-shaped" overlying strata structure and "ר-shaped" overlying strata structure were connected into one structure. If only the coal pillar area was taken into account, the coal pillar formed a "C-shaped" overlying strata structure (Figure 4(a)). At this time, the mining area was reduced at the rear working face. With variant width of reserved coal pillars and the influence of "O-shaped" overlying strata structure after reduction of mining area, the distribution of stress on the ultimate coal pillars with worked-out areas on four sides may be any of the following cases:

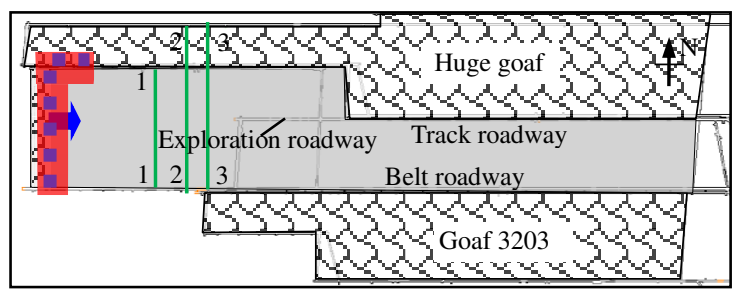

(a) Plan of " $\Gamma$-shaped" overlying strata structure

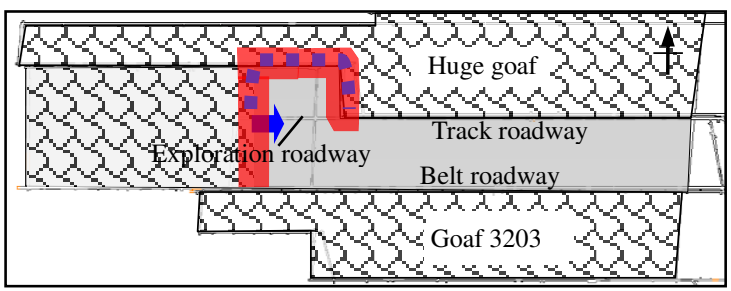

(a) Plan of "C-shaped" overlying strata structure 


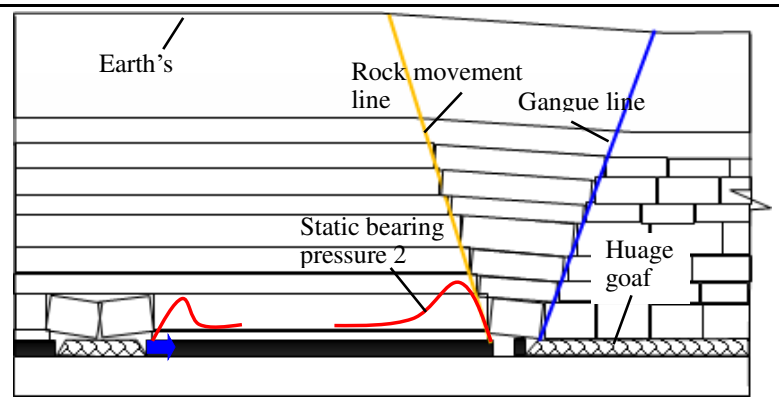

(b) Profile of "l" side of " $\Gamma$-shaped" overlying strata structure

Fig. 3 " $\Gamma$-shaped” overlying strata structure of coal pillar in mining toward worked-out area

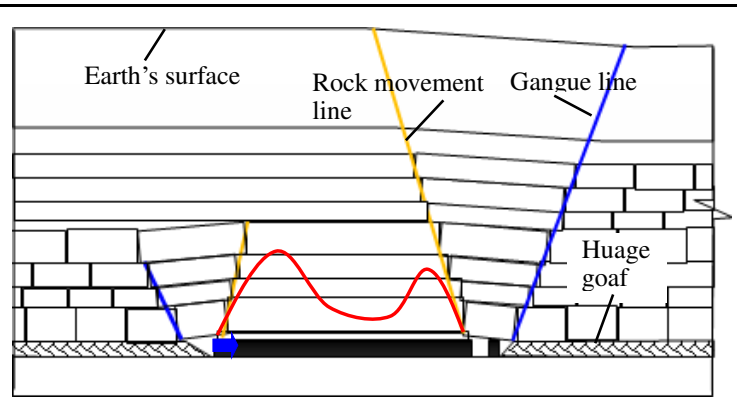

(b) Strike profile of "C-shaped" overlying strata structure

Fig. 4 "C-shaped" overlying strata structure of coal pillar in mining toward worked-out area

(1) Bilateral "saddle-shaped" distribution

If the width of reserved coal pillar is large and mining is advanced along the central exploration roadway after reduction of working face, since the strata structure of worked-out area in east, west and north sides is basically not changed due to isolation by central coal pillars during advancing of mining, the height of strata structure of south worked-out area is increased with advancing of mining and the formed bearing pressure is continuously superposed. When mining is advanced to the position as indicated in Figure 5(a), bilateral "saddle-shaped" bearing pressure is distributed on coal pillars with worked-our areas on four sides, as shown in Figure 5(b) and (c). Although the edge of these coal pillars is in plastic state, most of the central part is in elastic state. Therefore, the coal pillars are able to stay stable ${ }^{[11]}$.

(2) "Platform-shaped" distribution

If the width of reserved coal pillar is relatively small, when the reduced working face is advanced to the position as indicated in Figure 5(a), the peak bilateral bearing pressure superimposed on the coal pillar with worked-out areas on four sides. The strength of coal mass in the central elastic area of coal pillar is homogenized under high stress, resulting in evolution of superimposed bearing pressure into "platform-shaped" distribution, as shown in Figure 5(d) and (c). Such coal pillars are at the critical state of rock burst due to overall instability ${ }^{[12]}$.

(3) Overall "arch-shaped" distribution

If the width of reserved coal pillar is quite small, when the reduced working face is advanced to the position as indicated in Figure 5(a), the superimposition of peak bilateral bearing pressure on the coal pillar with worked areas on four sides is increased. The generated high stress constantly "corrodes" the strength of coal mass in the central elastic area, resulting in expansion and combination of plastic areas and the evolution of bearing pressure on corresponding coal pillars into overall "arch-shaped" distribution, as shown in Figure 5(f) and $(\mathrm{g})$. Such coal pillars are extremely instable and will easily cause rock burst in case of overall instability due to disturbance ${ }^{[13]}$.

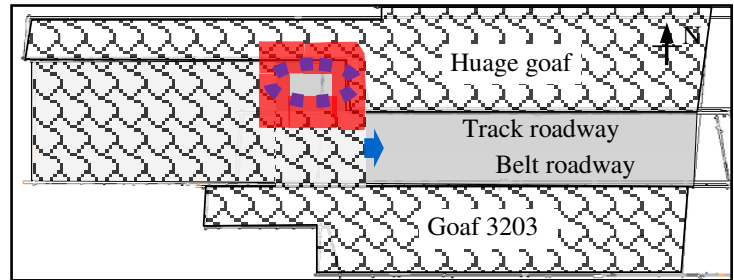

(a) Proadway of "O-shaped" overlying strata structure

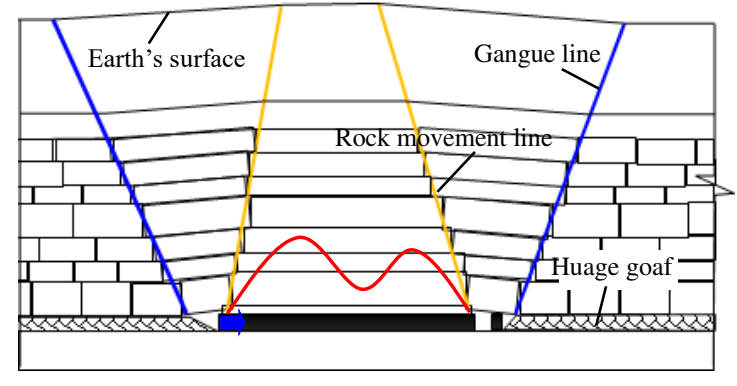

(b) Distribution of "saddle-shaped" bearing pressure along the strike 


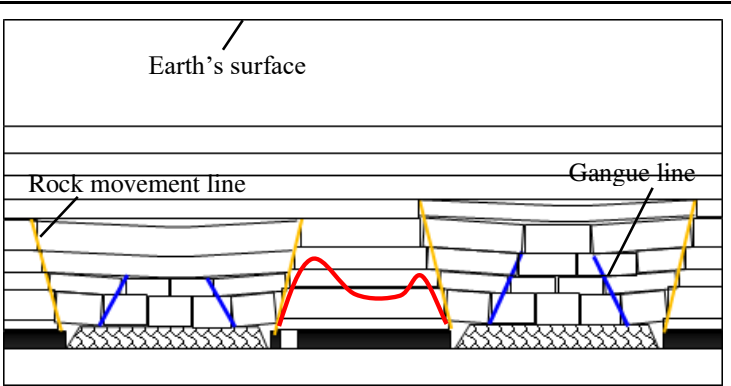

(c) Distribution of "saddle-shaped" bearing pressure along the inclination

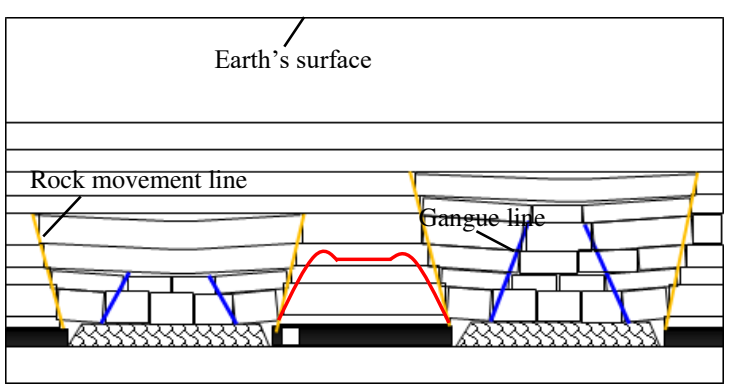

(c) Distribution of "platform-shaped" bearing pressure along the inclination

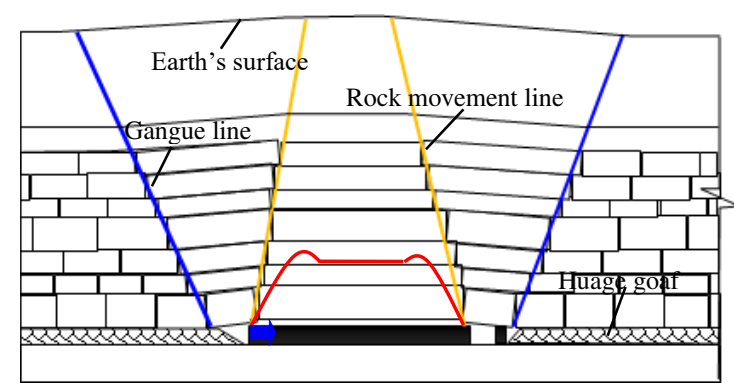

(d) Distribution of "platform-shaped" bearing pressure along the strike

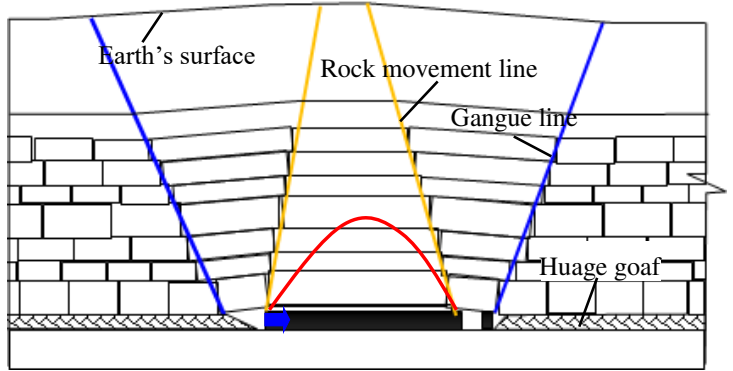

(f) Distribution of "arch-shaped" bearing pressure along the strike

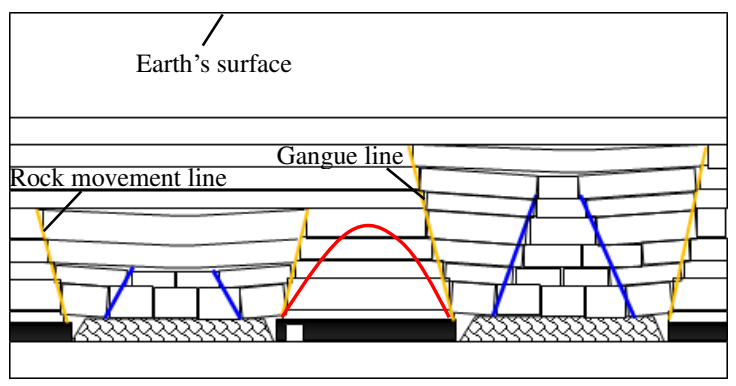

(g) Distribution of "arch-shaped" bearing pressure along the inclination

Fig. 5 Forms of distribution of bearing pressure of coal pillar in "O-shaped" overlying strata structure

\subsection{Mechanism of rock burst induced by coal pillars in worked-out area}

Upon foregoing analysis, the overlying strata of coal pillars of non-equal width isolated working face 3201 in worked-out area during mining evolved from "pre-mining static " $\neg$-shaped" structure $\rightarrow$ "C-shaped" structure $\rightarrow$ "O-shaped" structure". During evolution of overlying strata structure, the load of suspended stratum in caving zone, abscission zone and static load zone was constantly changing, resulting in evolution of stress on coal pillars from "inherent bearing pressure $\rightarrow$ superimposed bearing pressure on three sides $\rightarrow$ superimposed bearing pressure on four sides $\rightarrow$ concentrated high stress of coal pillars". When the width of reserved coal pillar is small than that in critical state (the distribution of stress on coal pillars is "platform-shaped") of rock burst, the high stress which acts on the coal pillars will be greater than the comprehensive compressive strength of coal mass on the coal pillars. As a result, the sudden instability of coal pillars will induce rock burst, which can be expressed with the following formula ${ }^{[14]}$ :

$$
\frac{P}{R}>1
$$

Where: $P$ is the high stress which acts on the coal pillars; $R$ is the comprehensive compressive strength of coal mass on the coal pillars.

\section{Reasonable width of reserved coal pillars of non-equal width isolated working face in worked-out area in deep mine}

3.1 Analysis of comprehensive compressive strength of coal pillars in critical state of rock burst 
Through analysis of evolution of overlying strata structure of coal pillar of non-equal width isolated working face 3201 during mining toward worked-out area, it can be learned that the coal pillars are in a critical state of rock burst due to overall instability when the superimposed bearing pressure on coal pillars is homogenized into "platform-shaped" distribution. Figure 6 is a schematic diagram of stress distribution and the state of corresponding coal mass in critical state of rock burst by coal pillars. It can be seen from the figure that plastic areas and elastic areas are formed in sequence from the edge to the in-depth area of coal pillar. The coal mass in the plastic area is in unidirectional or bidirectional stress state with poor bearing capacity. The in-depth area was elastic area. Due to being clamped by coal mass in surrounding plastic area and constrained by top and bottom stratum, the coal mass in elastic area is in a stress state in three directions with high strength and most bearing pressure is endured by the coal mass in this area. Let's set the compressive strength coefficient of coal mass in elastic area as $\varphi_{\max }$ and that of coal mass in elastic area as $\varphi_{\min }$. According to Wilson A.H.'s theory on inter-constraint between two areas, we obtain the expression of comprehensive compressive strength of coal mass on coal pillars:

$$
R=\bar{\varphi} \sigma_{c}=\left[\frac{L\left(x_{3}+x_{4}\right)+\left(B-x_{3}-x_{4}\right)\left(x_{1}+x_{2}\right)}{L B} \cdot \varphi_{\min }+\frac{\left(L-x_{1}-x_{2}\right)\left(B-x_{3}-x_{4}\right)}{L B} \varphi_{\max }\right] \sigma_{C}
$$

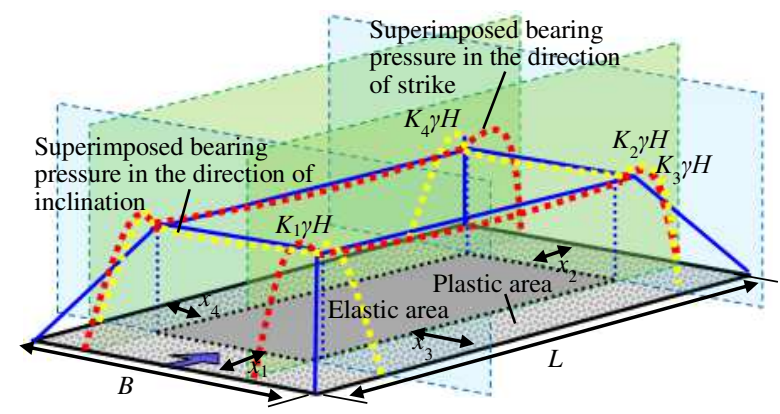

Fig. 6 Model of estimation of comprehensive compressive strength of coal pillar in critical state of rock burst

Where: $\bar{\varphi}$ is comprehensive compressive strength coefficient of coal mass; $\sigma_{\mathrm{c}}$ is uniaxial compressive strength of coal mass; $x_{i}(i=1,2,3)$ is the width of plastic area of coal pillar without man-made influence. According to ultimate balance theory, the width of plastic area ${ }^{[16]} x_{i}=\frac{m}{2 \vartheta f} \ln \frac{K_{i} \gamma H+C \cot \emptyset}{\vartheta(P+C \cot \varnothing)} ; K_{\mathrm{i}}$ is stress concentration coefficient $(i=1,2,3) ; P$ is resistance of roadway sidewall; $m$ is thickness of coal seam; $C$ is cohesion of coal mass; $\Phi$ is internal frictional angle of coal mass; $f$ is coefficient of friction between coal seam and top and bottom stratum; $\xi$ is triaxial stress coefficient, $\xi=(1+\sin \Phi) /(1-\sin \Phi)$.

\subsection{Estimation of mean stress endured by coal pillar in the critical state of rock burst}

Upon foregoing analysis, it's learned that the superimposed bearing pressure on coal pillars in the critical state of rock burst is homogenized into "platform-shaped" distribution. Thus, the load of suspended overlying rock in the four worked-out areas as endured by coal pillars can be converted into average stress for estimation. According to Figure 5(d) and (e), a model of estimation of average stress endured by coal pillars in critical state of rock burst is established, as shown in Figure 7. It can be seen from the figure that the average stress $P$ endured by coal pillars consists of three parts, namely, the average stress endured by suspended stratum in caving zone, abscission zone and static load zone in worked-out areas on four sides and denoted with $P_{\mathrm{K}}, P_{\mathrm{L}}$ and $P_{\mathrm{J}}$ respectively. The relation between $P$ and $P_{\mathrm{K}}, P_{\mathrm{L}}$ and $P_{\mathrm{J}}$ is as follows:

$$
P=P_{k}+P_{L}+P_{J}
$$

In the following, the expressions of $P_{\mathrm{K}}, P_{\mathrm{L}}$ and $P_{\mathrm{J}}$ are derived respectively.

(1) Expression of $P_{\mathrm{K}}$

According to Figure 7, the expression of average stress $P_{\mathrm{k}}$ on coal pillars generated by suspended stratum in caving zone is: 


$$
P_{k}=P_{k 1}+P_{k 2}+P_{k 3}+P_{k 4}
$$

Where, $P_{\mathrm{k} 1}, P_{\mathrm{k} 2}, P_{\mathrm{k} 3}$ and $P_{\mathrm{k} 4}$ are the average stress on coal pillars generated by rock mass in yellow, orange, deep blue and green areas as indicated in Figure 7 (representing half of suspended stratum in caving zone in the worked-out areas on four sides).

Through geometric calculation, the formula of estimation of $P_{\mathrm{k} 1}, P_{\mathrm{k} 2}, P_{\mathrm{k} 3}$ and $P_{\mathrm{k} 4}$ is:

$$
\left.\begin{array}{c}
P_{k 1}=\frac{\left[(\cot \alpha+\cot \beta) H_{1}+2 M_{1}\right] H_{1}(B+a) \gamma}{4 B L} \\
P_{k 2}=\frac{\left[(\cot \alpha+\cot \beta) H_{1}+2 M_{2}\right] H_{1}(B+a) \gamma}{4 B L} \\
P_{K 3}=\frac{\left[(\cot \alpha+\cot \beta) H_{2}+2 M_{3}\right] H_{2} \gamma}{4 B} \\
P_{k 4}=\frac{\left[(\cot \alpha+\cot \beta) H_{3}+2 M_{4}\right] H_{3} \gamma}{4 B}
\end{array}\right\}
$$

Where: $H_{1}$ is the height of carving zone in worked-out areas on the east and west side of coal pillar; $H_{2}$ and $H_{3}$ are the height of carving zone in worked-out areas on the south and north side of coal pillar; for common working face, in case of inadequate mining, the height of caving zone is equal to the ratio of thickness of coal seam $m$ and $(K-1)^{[17]}$ ( $K$ is the comprehensive bulking coefficient of caved rocks); $M_{1}, M_{2}, M_{3}$ and $M_{4}$ are the fracture length of basic roof in worked-our areas on the west, east, south and north sides; $\gamma$ is average volume weight of strata; $\alpha$ and $\beta$ are the movement angle of strata and gangue angel of caved strata; $B$ is length of coal pillar along the slope line; $L$ is length of coal pillar along the intersection line; a is the total width of track roadway and coal pillar in corresponding section.

(2) Expression of $P_{\mathrm{L}}$

According to Figure 7, the expression of average stress $P_{\mathrm{L}}$ on coal pillars generated by suspended stratum in caving zone is:

$$
P_{L}=P_{L 1}+P_{L 2}
$$

Where, $P_{\mathrm{L} 1}$ and $P_{\mathrm{L} 2}$ are the average stress on coal pillars generated by rock mass in red and blue areas as indicated in Figure 7 (representing half of suspended stratum in caving zone in the worked-out areas on south and north sides).

The formula of estimation of $P_{\mathrm{L} 1}$ and $P_{\mathrm{L} 2}$ is:

$$
\left.\begin{array}{l}
P_{L 1}=\frac{\left[\left(h_{2}+2 H_{2}\right) \cot \alpha+L_{1}\right] h_{2} \gamma}{2 B} \\
P_{L 2}=\frac{\left[\left(h_{1}+2 H_{3}\right) \cot \alpha+L_{2}\right] h_{1} \gamma}{2 B}
\end{array}\right\}
$$

Where: $h_{1}$ and $h_{2}$ are the thickness of abscission zone in worked-out areas on north and south sides of coal pillar; $L_{2}$ and $L_{1}$ are the length of corresponding worked-out areas along the slope line. According to the research of X.Luo ${ }^{[18]}$, before adequate mining of strata, if the maximum fracture height of overlying strata on the working face is about $1 / 2$ of the width of short side of worked-out areas, then $h_{1}=L_{2} / 2-H_{3}$ and $h_{2}=L_{1} / 2-H_{2}$

(3) Expression of $P_{\mathrm{J}}$

According to Figure 7, the expression of average stress $P_{\mathrm{J}}$ on coal pillars generated by suspended stratum (In Figure 7, the rock mass in purple area consists of half of suspended rock from the abscission zone to the earth's surface in the worked-out areas on four sides and the suspended rocks from the top of coal pillar to the earth's surface) in static load zone is:

$$
P_{J}=\left\{\begin{array}{c}
\left(L-2 H_{1} \cot \alpha\right)\left[B+a-\left(h_{1}+h_{2}+H_{2}+H_{3}\right) \cot \alpha\right] H_{1} \gamma+H_{1}^{2} \gamma(B+a) \cot \alpha+\frac{\left(h_{1}+H_{3}\right)^{2} \gamma L \cot \alpha}{2} \\
+\frac{\left(h_{2}+H_{2}\right)^{2} \gamma L \cot \alpha}{2}+\frac{\left(H_{1}-h_{1}-H_{3}\right) L \gamma\left[L_{2}+2\left(h_{1}+H_{3}\right) \cot \alpha\right]}{2}+\frac{\left(H_{1}-h_{2}-H_{2}\right) L \gamma\left[L_{1}+2\left(h_{2}+H_{2}\right) \cot \alpha\right]}{2}
\end{array}\right\} / B L
$$




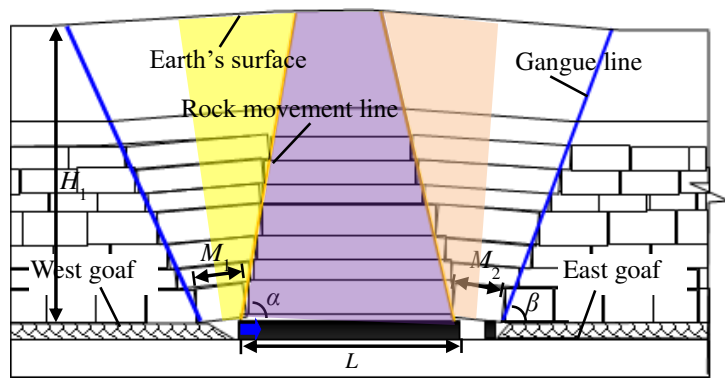

(a) Model of estimation of bearing stress along the strike

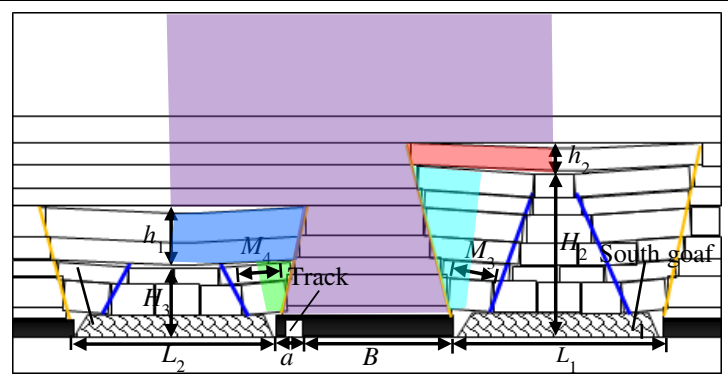

(b) Model of estimation of bearing stress along the inclination

Fig.7 Model of estimation of average bearing stress of cal pillar in critical state of rock burst

\subsection{Determination of reasonable width of coal pillar}

Based on the geological data and mining technical conditions of non-equal width isolated working face 3201, relevant parameters were obtained and substituted into foregoing formula for calculating reasonable width of coal pillars of isolated working face in mining toward worked-out area.

(1) Estimation of height of caving zone in worked-out area surrounded coal pillar

It can be learned from Figure 7(a) that there is adequate mining in the worked-out area on the east and west sides of coal pillar of the non-equal width isolated working face 3201 and the caving zone is expanded to the earth's surface. Therefore, $H_{1} \approx 670 \mathrm{~m}$. It can be learned from Figure $7(\mathrm{~b})$ that due to variance of width of worked-out area on south and north side of coal pillar and the influence by the basic roof of $30.7 \mathrm{~m}$ medium sandstone, the comprehensive bulking coefficient $K$ of rocks in caving zone in worked-out area on both sides is different. Let's set the value of $K$ as 1.05 and 1.14 respectively and thickness of coal seam $m=3.8 \mathrm{~m}$. Then, the caving height $\mathrm{H}_{2}$ and $\mathrm{H}_{3}$ of overlying rock in worked-out area on south and north sides are $H_{2} \approx 3.8 /(1.05-1) \approx 76 \mathrm{~m}$ and $H_{3} \approx 3.8 /(1.14-1) \approx 27 \mathrm{~m}$ respectively.

(2) Estimation of thickness of abscission zone in worked-out area surrounded coal pillar

It can be learned from Figure 7 that abscission zone only exists above the worked-out areas on south and north side of the non-equal width isolated working face 3201. Therefore, the thickness of abscission zone in the worked-out area on the two sides is calculated. The length of short side of worked-out area on south and north sides of coal pillar is $242 \mathrm{~m}$ and $88 \mathrm{~m}$ respectively. The fracture height of overlying strata in worked-out area on both sides is $121 \mathrm{~m}$ and $44 \mathrm{~m}$ respectively (the fracture height of overlying strata in worked-out area is half of the width of short side of worked-out area). Upon estimation, the height of caving zone in worked-out area on both sides is $76 \mathrm{~m}$ and $27 \mathrm{~m}$ respectively. Therefore, the thickness of abscission zone is $h_{2}=121-76=45 \mathrm{~m}$ and $h_{1}=44-27=17 \mathrm{~m}$ respectively.

(3) Other relevant parameters

The movement angle of strata $\alpha \approx 81^{\circ}$; the gangue angel of caved strata $\beta \approx 65^{\circ}$; the fracture length $M_{2}, M_{3}$, $M_{1}$ and $M_{4}$ of basic roof in worked-out area on east, south, west and north sides are $50 \mathrm{~m}, 45 \mathrm{~m}, 50 \mathrm{~m}$ and $41 \mathrm{~m}$ respectively; the average volume weight $\gamma$ of strata is $21 \mathrm{KN} / \mathrm{m}^{3}$; the length of coal pillar along slope line is $B=101.3 \mathrm{~m}$ (the vertical distance between exploration roadway and track roadway); the total width of track roadway and coal pillar in corresponding section $a=8.4 \mathrm{~m}$; compressive strength coefficient of coal mass in elastic area $\varphi_{\max }$ is set to 5 and that of coal mass in elastic area $\varphi_{\min }$ to 1.1 ; the width of elastic area $x_{2}, x_{3}$ and $x_{4}$ is $18 \mathrm{~m}$ (Formed through manual large-diameter pressure relief drilling; drilling parameters: hole depth $18 \mathrm{~m}$, row pitch $1 \mathrm{~m}$; diameter $110 \mathrm{~mm}$ ); foremost plastic area $x_{1}$ of working face is set to $10 \mathrm{~m}$; uniaxial compressive strength $\sigma_{\mathrm{c}}$ of coal mass to $20 \mathrm{MPa}$.

By substituting foregoing relevant parameters into formula (3) (8) and formula (2), the functional expression of $P$ and $R$ about $L$ is obtained. Then, they are substituted into formula (1) and with the ultimate state is taken, an equation of higher degree about $L$ is obtained. By solving the equation, the reasonable width of coal pillar of non-equal width isolated working face 3201 in worked-out area is obtained. In order to obtain 
the law of changes of width of coal pillar with $P$ and $R$, the range of width of coal pillar is set to [80,170]. The data within the range is rounded with an increment of $1 \mathrm{~m}$. Then, by substituting the obtained values into the function of $P$ and $R$, the curve of comprehensive compressive strength of coal pillars with different width and the endured average stress is obtained, as shown in Figure 8. It can be seen from the figure that when the width of coal pillar is smaller than $125 \mathrm{~m}$, the average stress endured is greater than the comprehensive compressive strength and there is risk that coal pillar will suffer overall instability and cause rock burst; on the contrast, if the comprehensive compressive strength of coal pillar is greater than the average stress endured, the coal pillar is relatively safe. Therefore, theoretically, the reasonable width of coal pillars of non-equal width isolated working face 3201 in worked-out area is determined at $125 \mathrm{~m}$. Nonetheless, considering the influence of disturbance and abnormality of roof during mining, the width of reserved coal pillars is finally determined to be $130 \mathrm{~m}$.

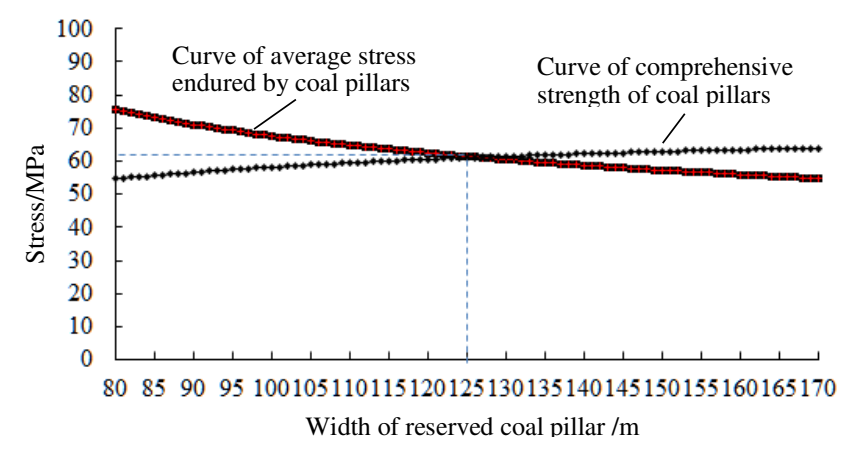

Fig. 8 Curve of comprehensive strength and average bearing stress of coal pillars with different width

\section{Engineering verification}

To verify whether it is reasonable set the width of reserved coal pillars of non-equal width isolated working face 3201 in worked-out area at $130 \mathrm{~m}$, field test was conducted by arranging stress testing points inside the coal pillars. There were two test points with a burial depth of $8 \mathrm{~m}$ and $14 \mathrm{~m}$ respectively (see Figure 1). Figure 9 shows the curve of stress of coal pillars with different width at test points during mining at the working face. It can be seen from the figure that when the width of coal pillar is $672 \mathrm{~m} 336 \mathrm{~m}$, the curve of stress is stable at the test points of $8 \mathrm{~m}$ and $14 \mathrm{~m}$, indicating that the comprehensive compressive strength of coal pillar is strong and able to endure the applied stress. When the width of coal pillar is $336 \mathrm{~m}$, the stress at the test point of $14 \mathrm{~m}$ starts to raise while that at the test point of $8 \mathrm{~m}$ remains stable (in plastic area). With gradual reduction of width of coal pillar, the stress at the test point of $14 \mathrm{~m}$ gradually increases more significantly; when the width of coal pillar is about $165 \mathrm{~m}$, the stress at the test point of $14 \mathrm{~m}$ reached $10 \mathrm{MPa}$ and yellow alarm is triggered while the stress at the test point of $8 \mathrm{~m}$ also raises (the coal mass in the plastic area is compressed due to high stress and resumed bearing capacity). Then, the width of coal pillar is maintained at $130 \mathrm{~m}$ and the stress at the test point of $14 \mathrm{~m}$ continued to raise and constantly remained at a high level after red alarm is triggered. Nonetheless, no rock burst occurs to coal pillars. The foregoing dynamic monitoring of stress on the field verified that it is reasonable to set the width of reserved coal pillar of non-equal width isolated working face 3201 in worked-out area at $130 \mathrm{~m}$. 


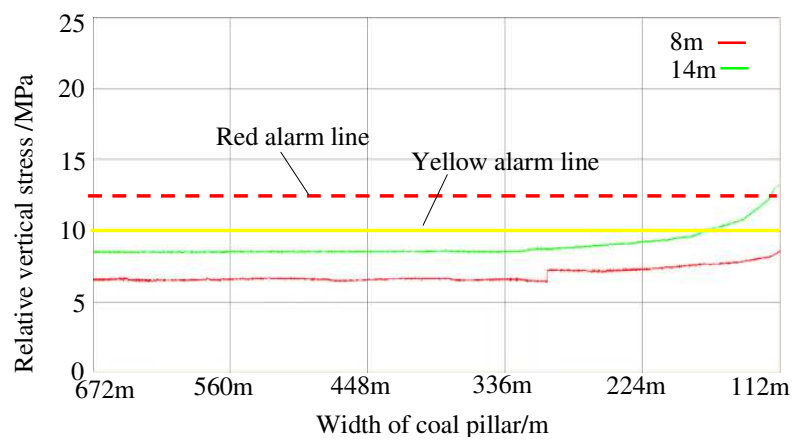

Fig. 9 Curve of stress at monitoring point of coal pillars with different width

\section{Conclusion}

(1) Due to irregular shapes of non-equal width isolated working face and complicated distribution of its surrounding worked-out areas in deep mine, the coal pillar in worked-out area changes from pillars with goaf on two sides $\rightarrow$ pillars with goaf on three sides $\rightarrow$ pillars with goaf on four sides and corresponding overlying strata evolves from pre-mining static "ᄀ -shaped” structure $\rightarrow$ “C-shaped” structure $\rightarrow$ “O-shaped” structure.

(2) The variation of width of reserved coal pillar of non-equal width isolated working face in worked-out area results in three different distribution of spatial stress: "saddle-shaped" distribution, "platform-shaped" distribution and "arch-shaped" distribution. Where, "platform-shaped" distribution is at the critical state of rock burst. At this time, if the stress on the coal pillar is greater then its comprehensive strength, the sudden instability will induce a rock burst.

(3) By establishing a bearing and load model of coal pillars at critical state of a rock burst and based on the equilibrium relation, an method for estimating reasonable width of coal pillars of isolated working face in worked-out area in deep mine is derived and verified through field practice.

(4) As often as not, the geological and mining conditions of isolated working face in deep mine are complicated, resulting in constant changes of bearing capacity and load of coal pillars in the critical state of rock burst which are difficult to be quantified. In this article, the method as proposed based on the spatial structure of overlying strata for estimation of reasonable width of coal pillars of isolated working face in worked-out area is preliminary and subject to further optimization in engineering practice.

\section{Acknowledgements}

The authors gratefully acknowledge financial support from Fund of Key Scientific Research Project of Colleges and Universities in Henan Province (Grant no. 19A440012). The authors thank the anonymous reviewers for constructive comments that helped to improve the quality of the paper.

\section{References}

1. Liu, J. H., Cao,Y. Q., Wei, Z. Q., Shen, W.(2015). Research on reasonable width of partition pillar close to goaf heading mining in thick seam of deep shaft. Chinese Journal of Rock Mechanics and Engineering, 34(supp2), 4269-4277.

2. Yang, W. L., Jiang, F. X., Yang, P., Zhai, M. H., Wang, Y. B. et al. (2017). Prevention of rockburst in large island longwall panels induced by instability of super-thick magmatic strata. Chinese Journal of Rock Mechanics and Engineering, 36(supp1), 3382-3391.

3. Wang, H. W., Jiang, Y. D., Yang, Z. D., Liu, S. (2012). Multi-variable assessment of coal bump risk during extraction of an island longwall panel. Journal of China Coal Society, 37(11), 1790-1795.

4. Jiang, F. X., Wang, T. X., Wang, H. J., Wu, S. L. (2005). Multi-variable assessment of coal bump risk during extraction of an island longwall panel. Chinese Journal of Geotechnical Engineering, 27(9), 1101-1104.

5. Liu, C. Y., Huang, B. X., Meng, X. J., Yang, P. J., Chen, L. G. (2007). Research on abutment pressure distribution law of overlength isolated fully-mechanized top coal caving face. Chinese Journal of Rock Mechanics and Engineering, 26(supp1), 2761-2766.

6. Nie, J. W., Wang, Q. N., Xu, J. F. (2012). Determination on coal pillar width of gateway driving along goaf in island seam coal mining face of deep mine," Coal Engineering, (6), 11-13. 
7. Huang, B. X., Liu, C. Y., Zheng, B. S., Cheng, Q. Y. (2007). Distribution abutment pressures on laneway pillars for superwide isolated fully mechanized top coal caving face. Chinese Journal of Geotechnical Engineering, 29(6), 932-937.

8. Ren, J. F., Gao, M. S., Li, Y. J., Zhao, Y. G., Guo, Y. S. (2009). Analysis on numerical simulation of rational width for coal pillar in different sections of fully mechanized coal mining face in seam island. Coal Science and Technology, 37(6), 27-30.

9. Chen, X. Z. (2009). Analysis of deformation rules of roadway in narrow pillar surrounded by gob," Coal Science and Technology, 14(5), 88-89.

10. Qi, Q. X., Li, X. L., Zhao, S. K. (2013). Theory and practices on stress control of mine pressure bumping.Coal Science and Technology, 41(6), 1-5.

11. Zhang, M., Li, K. Q., Jiang, F. X., Yang, G. D., Xu, S. J. et al. (2016). Study on the width of isolated coal face with rock-burst hazards based on the theory of overburden structure. Metal Mine, (4), 62-66.

12. Wang, G. A., Zhu, S. T., Jiang, F. X., Wang, B. Q., Zhou, T. et al. (2019). Mechanism of rock burst induced by overall instability of isolated coal and its prevention in large well at thousands-kilometer underground. Journal of Mining \& Safety Engineering, 36(5), 968-976.

13. Feng,Y., Jiang, F. X., Li, J. D. (2015). Evaluation method of rock burst hazard induced by overall instability of island coal face. Journal of China Coal Society, 40(5), 1001-1007.

14. Zhang, M., Jiang, F. X. Li, K. Q., Wang, C. W., Wu, X. G. et al. (2017). Study of the compatible deformation and stability of the system of super thick strata and coal pillars. Chinese Journal of Rock Mechanics and Engineering, 36(2), 326-334.

15. Wang, X. C., Huang, F. C., Zhang, H. X., Zhang, L. G. (2002). Discussion and improvement for A H Wilson at coal pillar design. Journal of China Coal Society, 27(6), 604-608.

16. Qian, M. G., Shi, P. W., Xu, J. L.(2010). Ground pressure and strata control[M]. Xuzhou: China University of Mining and Technology Press.

17. LUO, X., HATHERLY, P. (1998). Application of microseismic monitoring to characterise geomechnic conditions in longwall mining[J]. Exploration Geophysics, (29), 489-493. 
Figures

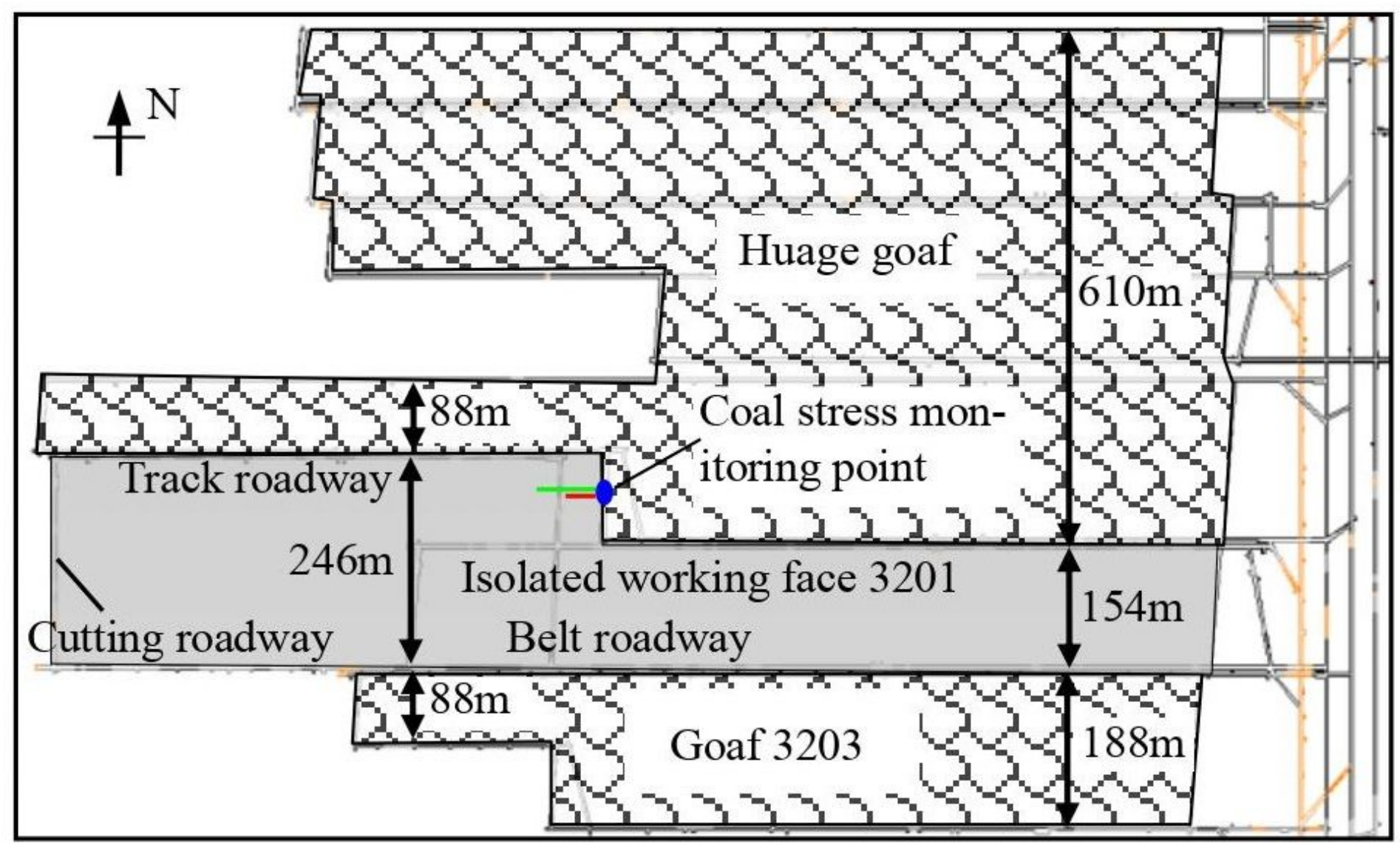

Figure 1

Plane of non-equal width isolated working face 3201 


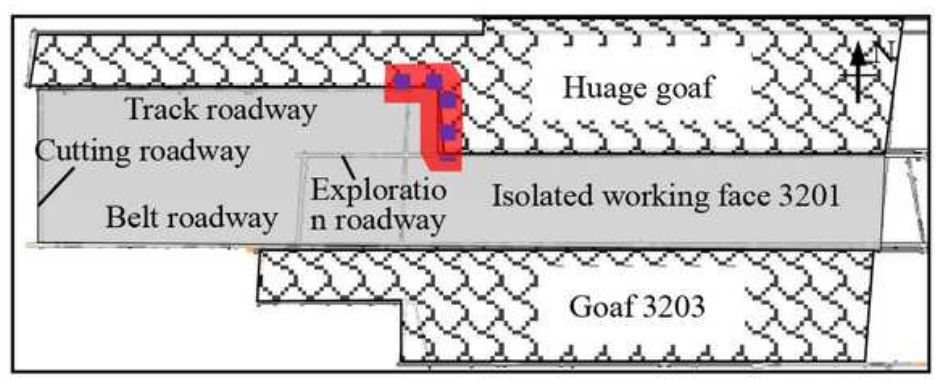

(a) The plan of "ᄀ -shaped" overlying strata structure

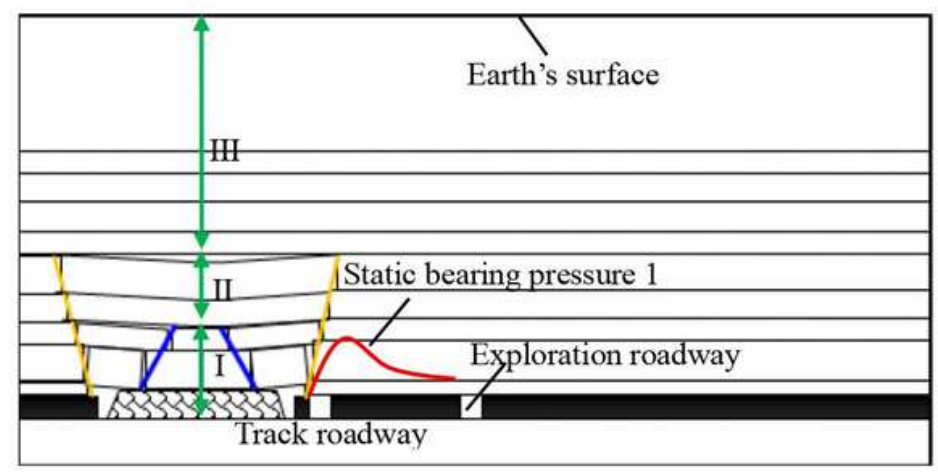

(b) Profile of "-" side of "ר -shaped" overlying strata load structure

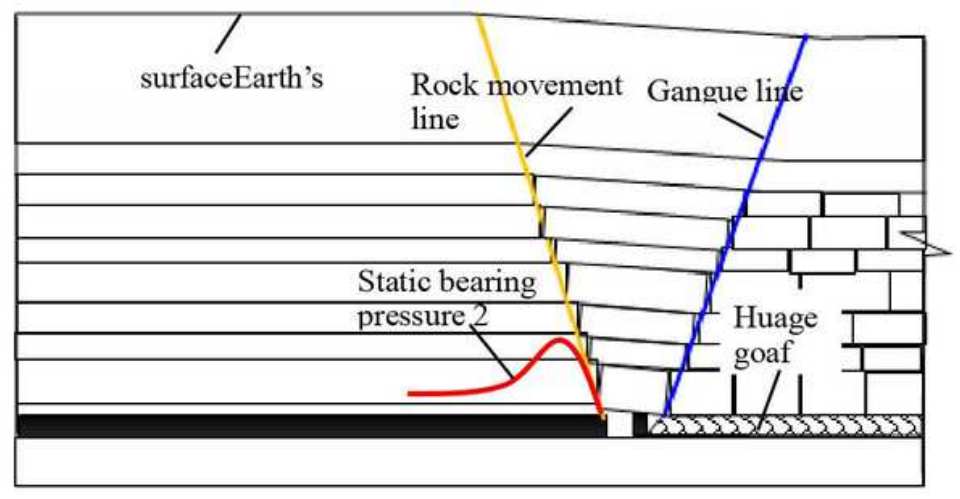

(c) Profile of "I" side of "ᄀ-shaped" overlying strata load structure

\section{Figure 2}

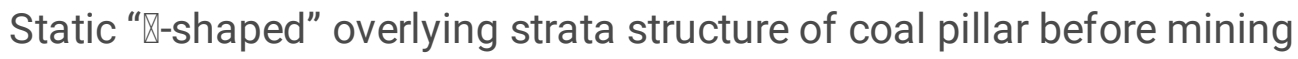




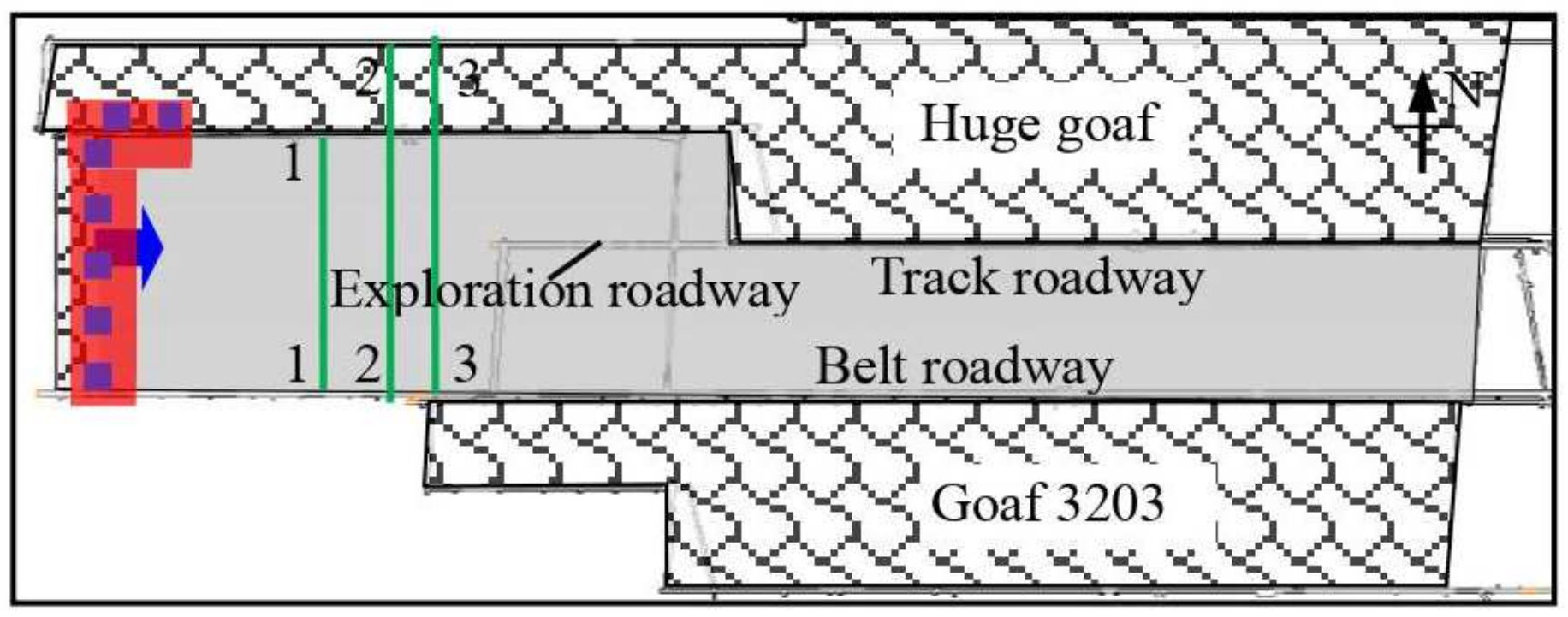

(a) Plan of " $\Gamma$-shaped" overlying strata structure

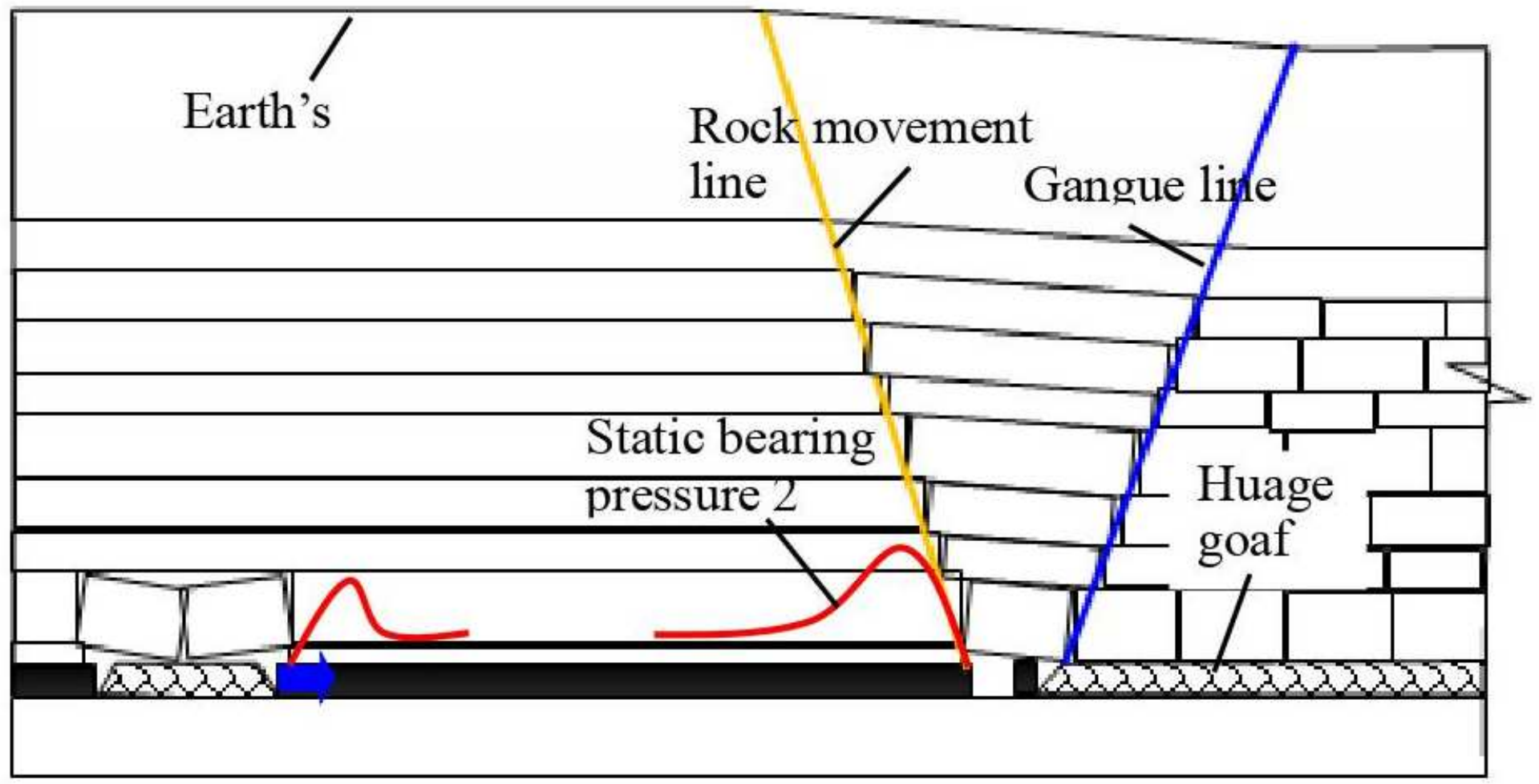

(b) Profile of " $I$ " side of " $\Gamma$-shaped" overlying strata structure

Figure 3

“凹-shaped” overlying strata structure of coal pillar in mining toward worked-out area 


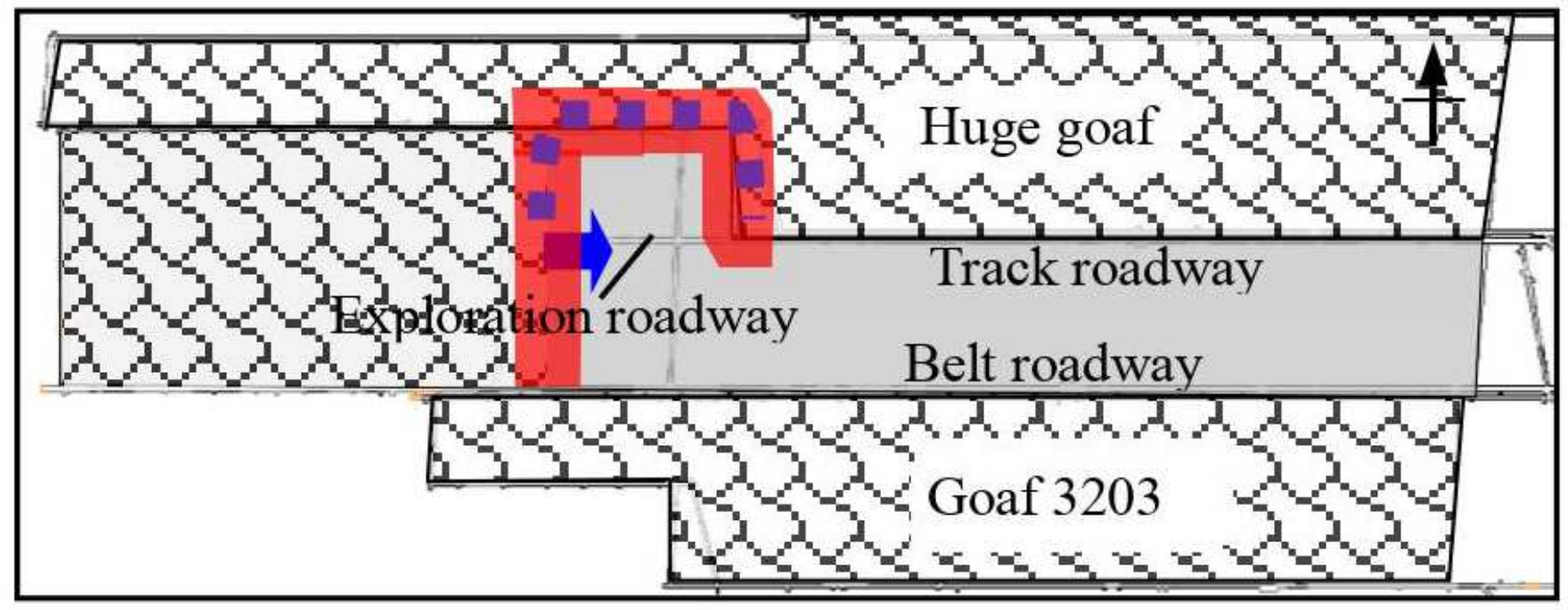

(a) Plan of "C-shaped" overlying strata structure

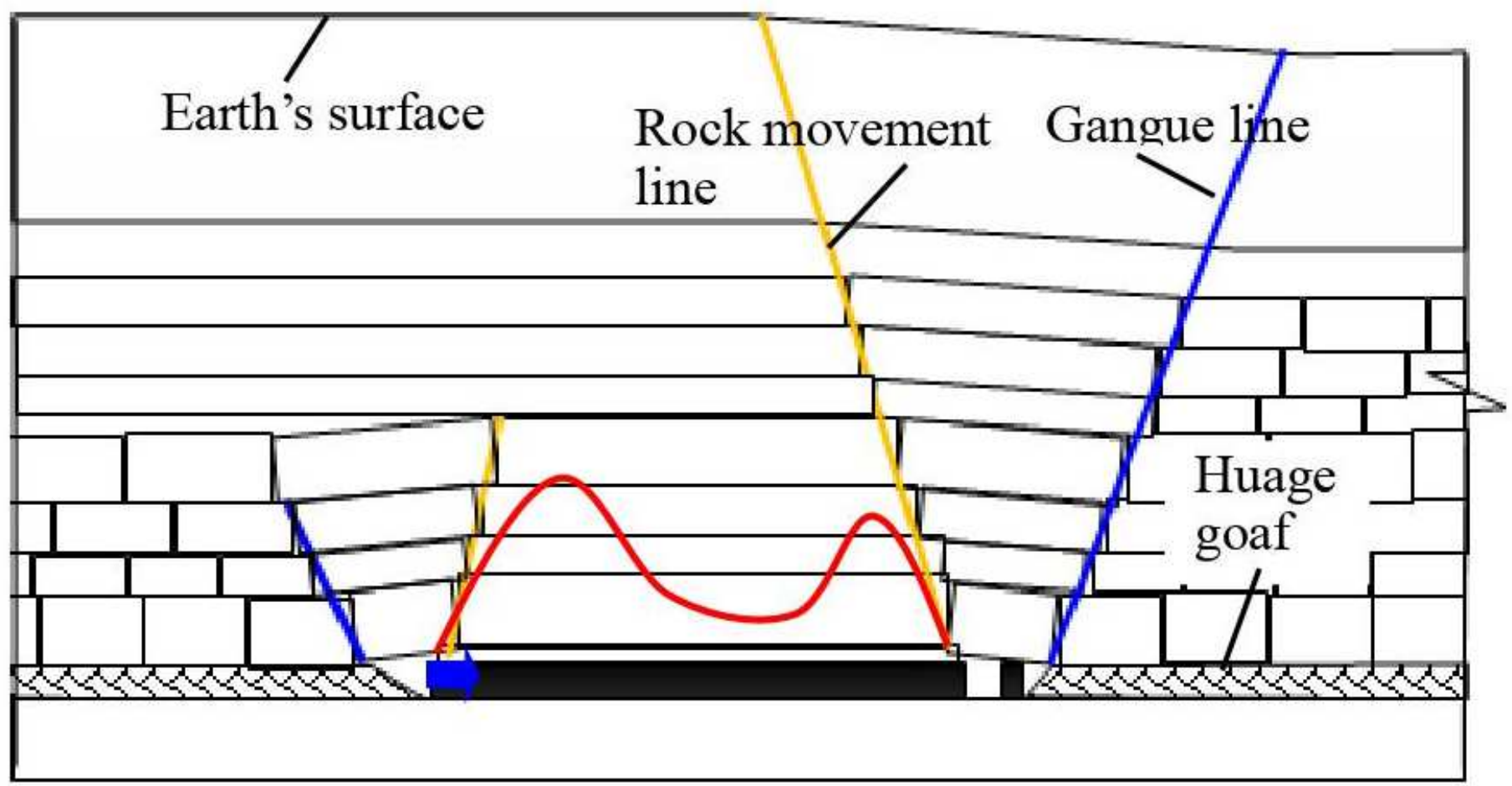

(b) Strike profile of "C-shaped" overlying strata structure

Figure 4

Fig. 4 "C-shaped" overlying strata structure of coal pillar in mining toward worked-out area 


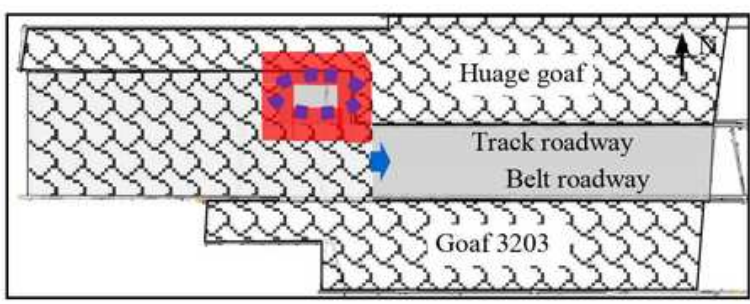

(a) Proadway of "O-shaped" overlying strata structure

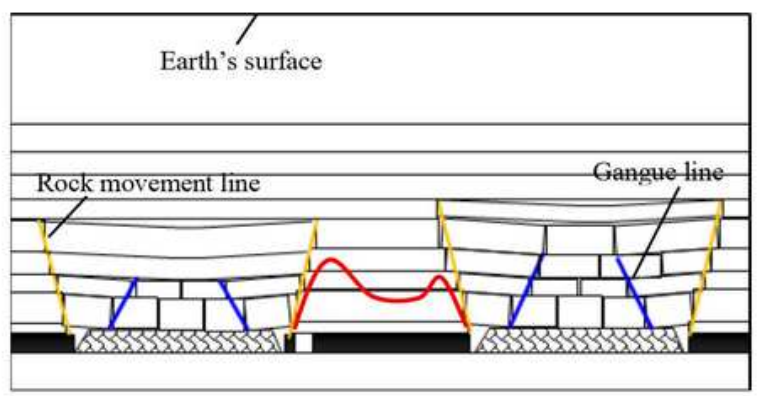

(c) Distribution of "saddle-shaped" bearing pressure along the inclination

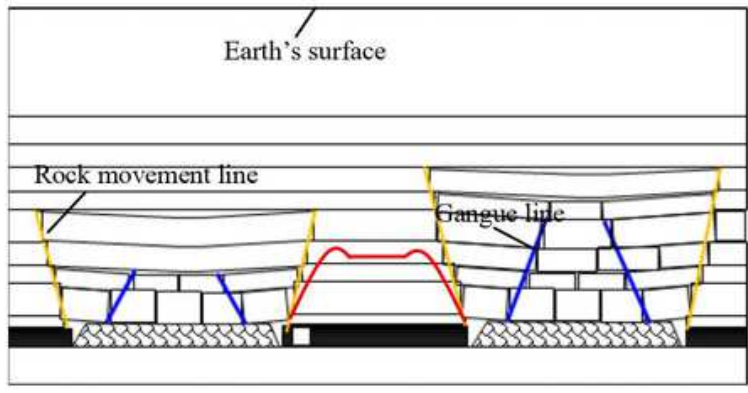

(c) Distribution of "platform-shaped" bearing pressure along the inclination

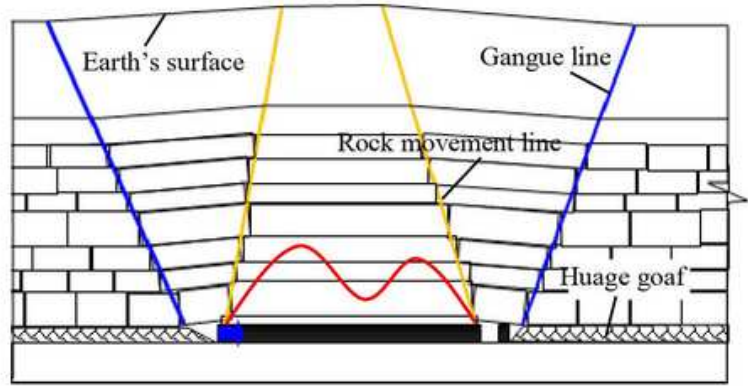

(b) Distribution of "saddle-shaped" bearing pressure along the strike

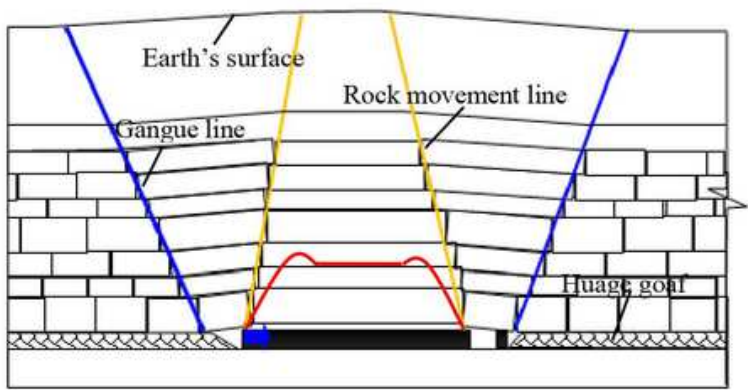

(d) Distribution of "platform-shaped" bearing pressure along the strike

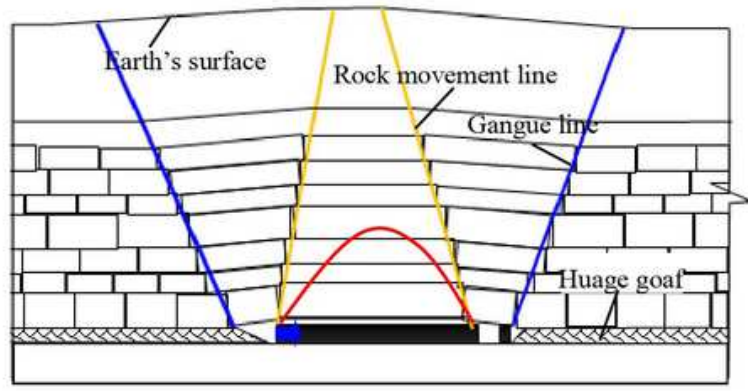

(f) Distribution of "arch-shaped" bearing pressure along the strike

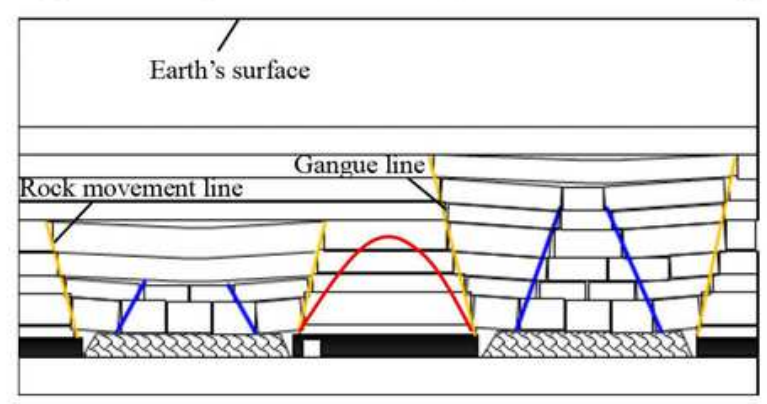

(g) Distribution of "arch-shaped" bearing pressure along the inclination

\section{Figure 5}

Forms of distribution of bearing pressure of coal pillar in "O-shaped" overlying strata structure 


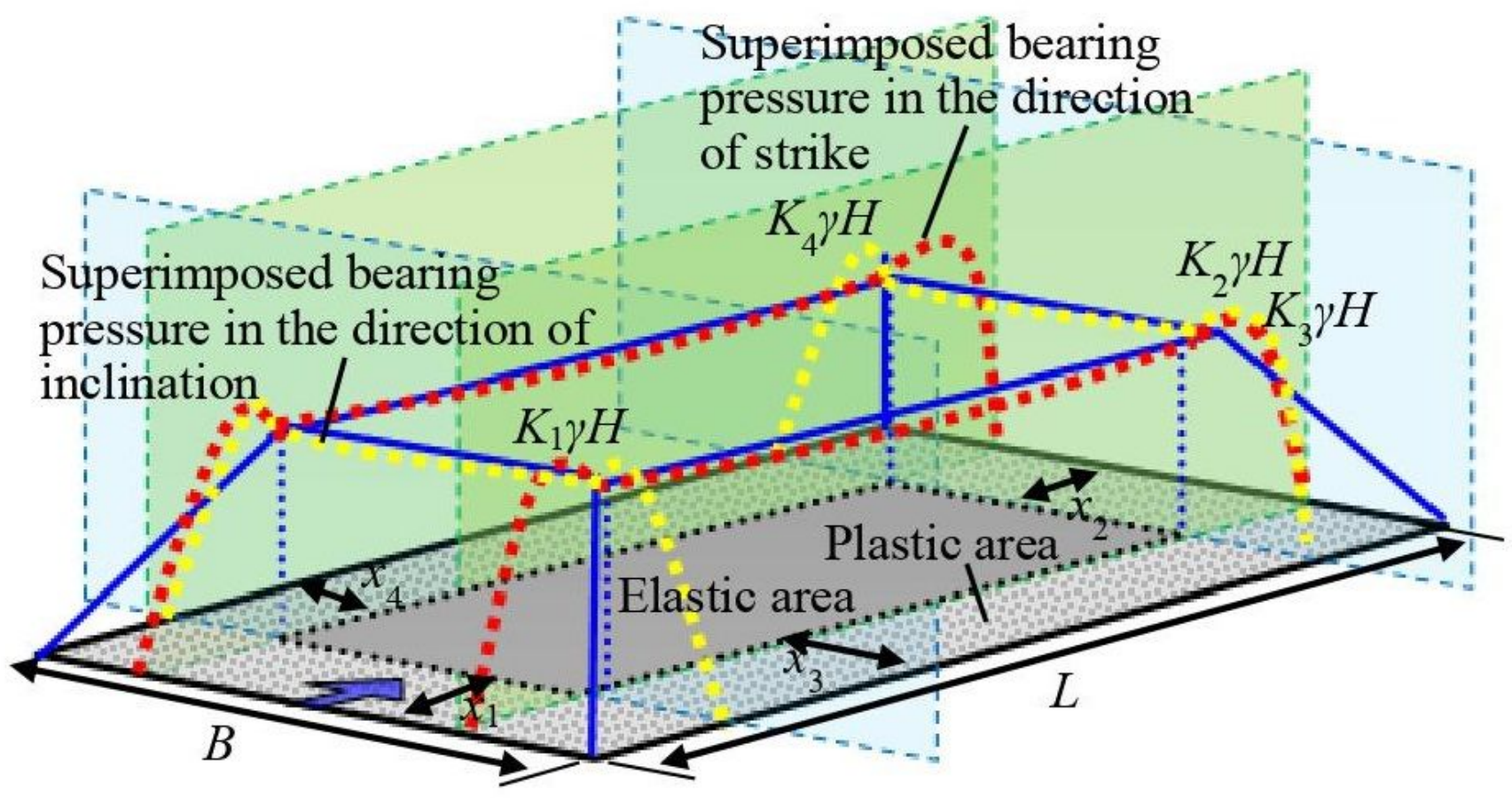

Figure 6

Please see the Manuscript PDF file for the complete figure caption

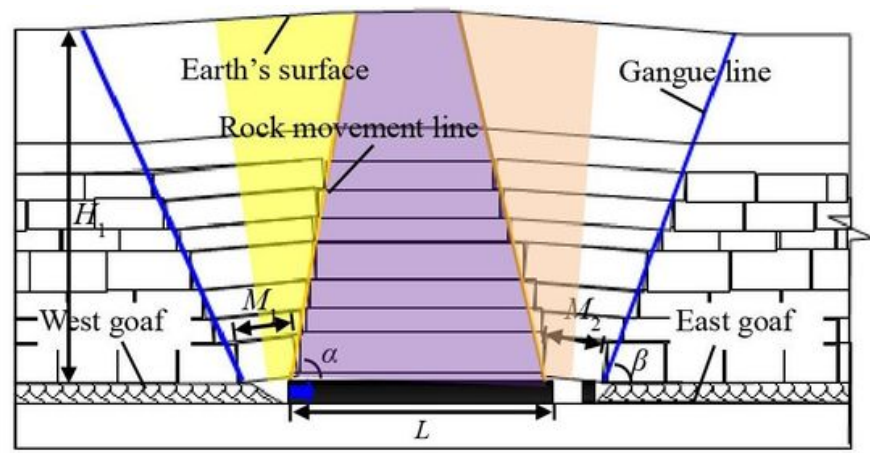

(a) Model of estimation of bearing stress along the strike

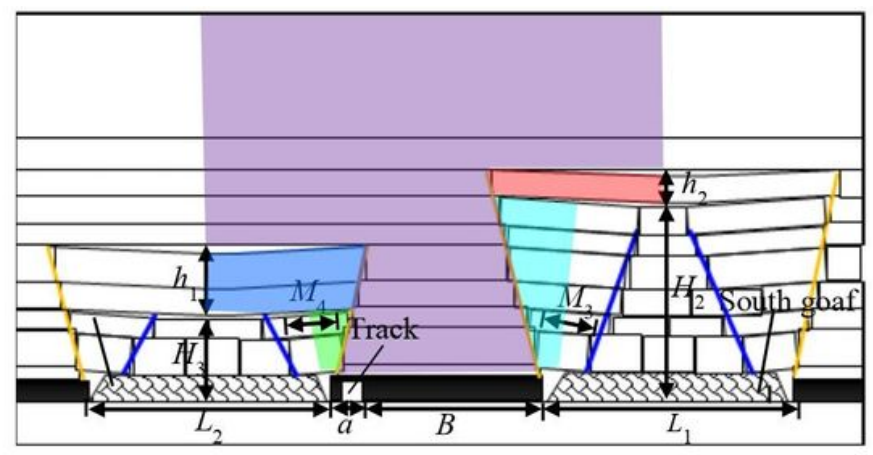

(b) Model of estimation of bearing stress along the inclination

\section{Figure 7}

Model of estimation of average bearing stress of cal pillar in critical state of rock burst 


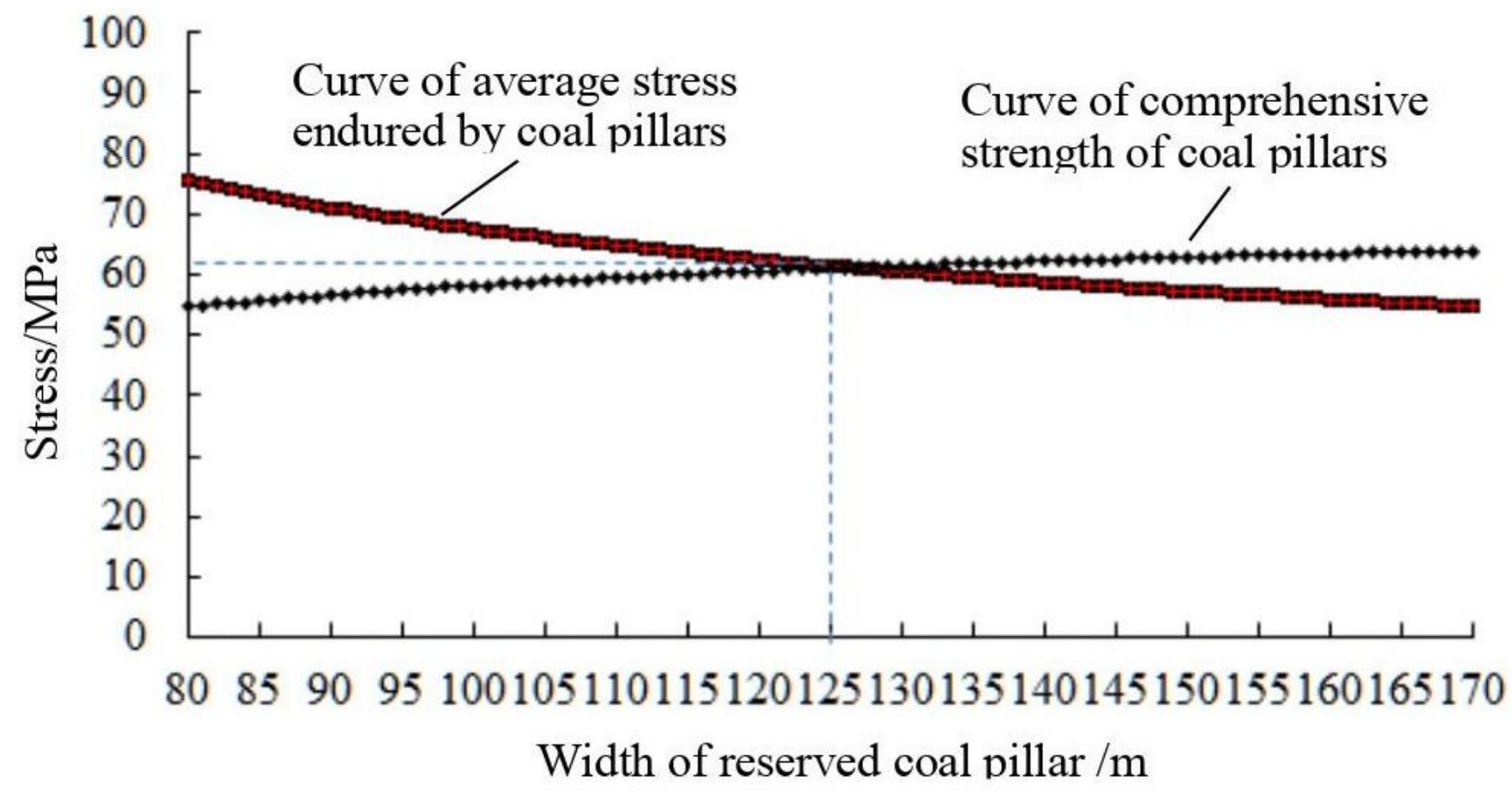

Figure 8

Curve of comprehensive strength and average bearing stress of coal pillars with different width

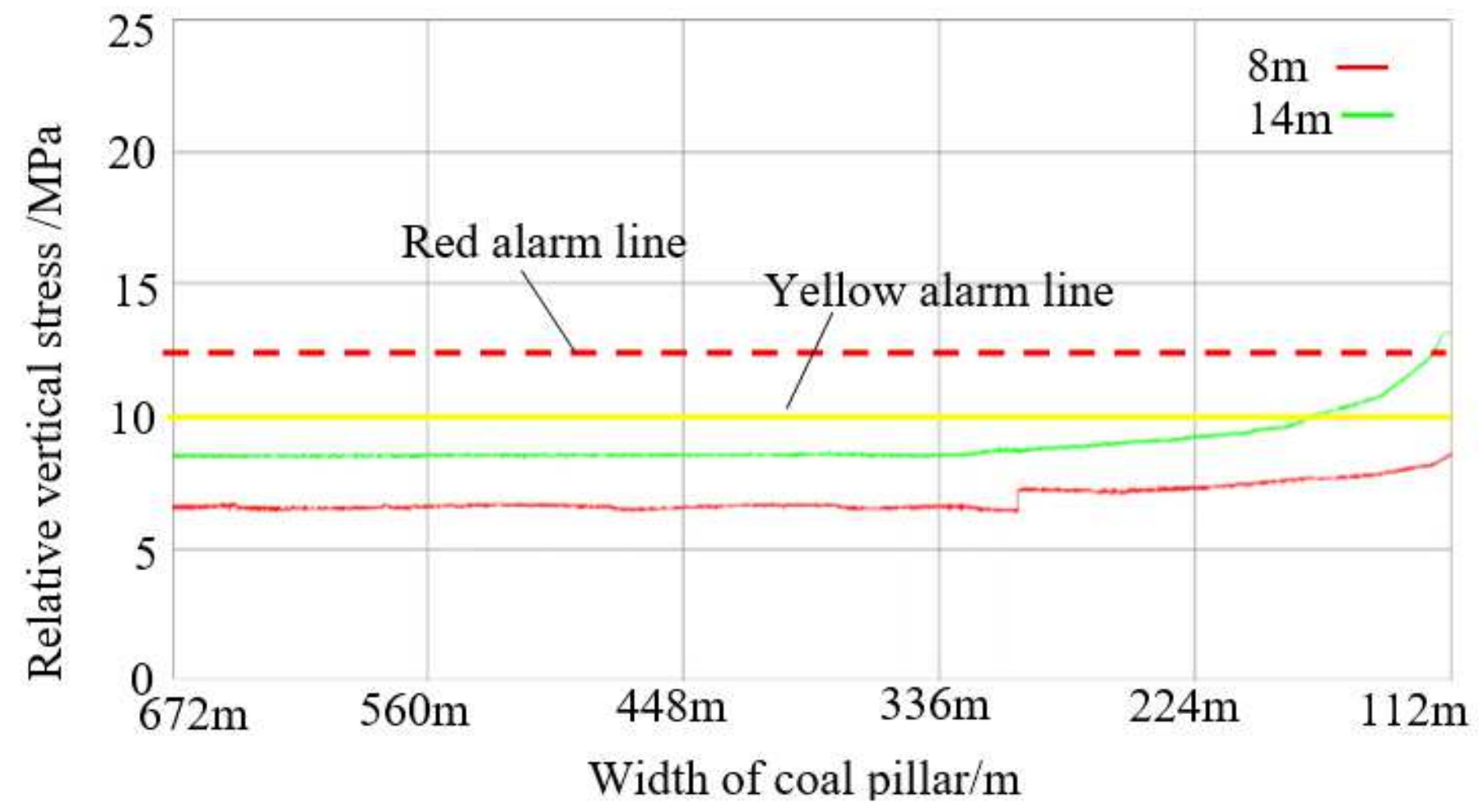


Figure 9

Curve of stress at monitoring point of coal pillars with different width 